\title{
Prognostic Value of Neutrophil To Lymphocyte Ratio In Acute Ischemic Stroke Patients Treated With Intravenous Thrombolysis: A Meta-Analysis
}

\author{
Chengbing Wang \\ China-Japan Union Hospital of Jilin University \\ Qian Zhang \\ China-Japan Union Hospital of Jilin University \\ Mingwei Ji \\ China-Japan Union Hospital of Jilin University

\section{Jing Mang} \\ China-Japan Union Hospital of Jilin University \\ Zhongxin Xu ( $\nabla$ xuzhongxin@jlu.edu.cn ) \\ China-Japan Union Hospital of Jilin University
}

\section{Research Article}

Keywords: acute ischemic stroke, neutrophil to lymphocyte ratio, intravenous thrombolysis, hemorrhagic transformation, functional outcome, meta-analysis

Posted Date: February 13th, 2021

DOI: https://doi.org/10.21203/rs.3.rs-189563/v1

License: (c) (1) This work is licensed under a Creative Commons Attribution 4.0 International License. Read Full License 


\section{Abstract}

Background: The neutrophil to lymphocyte ratio (NLR) has been shown to be an important independent inflammatory indicator in stroke. The relationship between NLR and poor prognostics in acute ischemic stroke (AIS) patients who received intravenous thrombolysis (IVT) still unclear. The purpose of this meta-analysis was to evaluate the association between NLR and poor prognosis after IVT. Furthermore, we aim to concluded whether admission NLR or post-IVT NLR play a role in AIS.

Methods: Pubmed, Embase, Wed of Science and China National Knowledge Infrastructure were searched for relevant articles until October 7, 2020. Cohort and case-control studies were included if related to NLR in AIS patients treated with IVT. Odds ratios (ORs) and $95 \%$ confidence intervals ( $95 \% \mathrm{Cls}$ ) were pooled to estimate the relationship between NLR and poor prognosis after IVT. A random effects model was used to calculate the pooled data.

Results: Twelve studies, including 3641 patients met the predefined inclusion criteria. Higher NLR levels were associated with an increased risk of hemorrhagic transformation $(\mathrm{HT})(\mathrm{OR}=1.33,95 \% \mathrm{Cl}=1.14-1.56, P<0.001)$ and 3-month poor functional outcome (OR=1.64,95\% $\mathrm{Cl}=1.38-1.94, P<0.001)$ in AIS patients receiving IVT. Subgroup analysis of HT suggested that admission NLR levels rather than post-IVT NLR levels was associated with higher risk of HT $(\mathrm{OR}=1.33,95 \% \mathrm{Cl}=1.01-1.75, \mathrm{P}=0.039)$. But There had no statistically significant difference between higher NLR levels and 3-month mortality $(\mathrm{OR}=1.14,95 \% \mathrm{Cl}=0.97-1.35$, $P=0.120)$.

Conclusions: High NLR can predict HT and 3-month poor functional outcome in AIS patients received IVT. Admission NLR rather than post-IVT NLR was independent risk factor of increased risk of HT.

\section{Background}

Stroke is a leading cause of death and acquired disability worldwide, which brings huge psychological and economic burden to patients and society[1]. Ischemic stroke accounts for about 70\% of all stroke types[1]. Intravenous recombinant tissue plasminogen activator (rt-PA) is an effective treatment for AIS patients within 4.5h after onset[2]. However, there are still some patients who received IVT with poor functional outcome, of which HT is the most common and serious complication of IVT[3].

Inflammation is involved in early brain injury and tissue repair after stroke at a later stage[4]. NLR is a readily available, repeatable new inflammatory biomarker. Neutrophils were rapidly recruited to ischemic area after AIS[5]. Neutrophils released reactive oxygen species (ROS) and a variety of inflammatory mediators[6]. This aggravated brain injury and increased the risk of HT. Some types of lymphocytes played an important role in the protective mechanism of ischemic brain tissue[7]. However, the systemic immunosuppression and stress response decreased not only in the number but also the activity of lymphocytes[8]. Previous meta-analyses have shown that baseline NLR was associated with HT and 3-month poor functional outcome after ischemic stroke $[9,10]$. In addition, recently studies have shown that NLR was a dynamic variable, and post-IVT NLR can better predict HT and poor functional outcome than admission NLR[11, 12]. However, the predictive value of NLR in AIS patients receiving IVT remained controversial. Furthermore, whether admission NLR or post-IVT NLR play a role in AIS remained unclear.

The aim of this meta-analysis was to comprehensively evaluate the relationship between NLR and poor prognosis in AIS patients receiving IVT. Furthermore, we aim to concluded whether admission NLR or post-IVT NLR play a role in AIS.

\section{Methods}

\section{Search strategy}

This meta-analysis was reported based on the Preferred Reporting Items for Systematic Reviews and Meta-Analyses (PRISMA) Statement[13]. We searched Pubmed, Embase, Wed of Science and China National Knowledge Infrastructure for relevant studies until October 7, 2020. No language restrictions were imposed. We used the following keywords and combine their synonyms: "neutrophil to lymphocyte ratio", "intravenous thrombolysis", "tissue plasminogen activator". Take Pubmed as an example, the complete search strategy was: ((neutrophil to lymphocyte ratio[Title/Abstract]) OR (NLR[Title/Abstract])) AND 
(("Tissue Plasminogen Activator"[Mesh]) OR (tissue plasminogen activator[Title/Abstract]) OR (alteplase[Title/Abstract]) OR (rtPA[Title/Abstract]) OR (intravenous thrombolysis[Title/Abstract])). Literature reference lists of included studies were also screened to supplement the search.

\section{Study selection}

Studies that met the following inclusion criteria were selected: (1)the subjects were AIS patients receiving IVT; (2) NLR was measured on admission or after IVT; (3) at least one of the following outcomes was reported: HT, poor functional outcome (modified Rankin Scale $\geq 3$ ) and mortality; (4) the study design was a cohort or a case-control study. Animal studies, repeatedly published or data overlapping studies, reviews, case reports, conference abstracts, letters, and unrelated articles were excluded. Two independent reviewers screened the titles and abstracts, and reviewed the full text of the studies that may meet the inclusion criteria. All disagreements were resolved by consulting another reviewer.

\section{Data extraction and quality assessment}

Two reviewers extracted the data independently and cross-checked them, and all disagreements were resolved through discussion. The following data were collected: name of the first author, publication year, country, number of patients, gender, age, blood sample collection time, best cut-off value of NLR, baseline NIHSS score, odds ratio (OR) and 95\% confidence interval (Cl) of HT, poor functional outcome and mortality. The multivariate regression analysis was used to calculate the pooled OR if both univariate and multivariate regression analyses were available in the study. We used the Newcastle-Ottawa Scale (NOS) to evaluate the quality of cohort studies and case-control studies. The study with the highest quality scored 9 points, which scored 7 or more regarded as high quality[14].

\section{Statistical analysis}

A random-effects model was used to calculate the pooled OR and $95 \% \mathrm{Cl}$. $P$ value $<0.05$ was regarded as statistically significant. We used $\chi^{2}$ and $\mathrm{I}^{2}$ tests to evaluate heterogeneity between studies, $\chi^{2}$ test result of $P$ value $<0.1$ and $\mathrm{I}^{2}$ test result of $>50 \%$ meaning significant heterogeneity $[15,16]$. Moreover, we conducted a sensitivity analysis to assess the contribution of individual studies on the overall effect by excluding one study at a time in chronological order. Funnel chart was used to detect publication bias and Egger test was used to evaluate the symmetry of funnel chart, and $P$ value $<0.05$ implying significant publication bias[17]. The trim-and-fill method was used to estimate the effect of publication bias on the results part[18]. All statistical analyses were performed by STATA version 16.0 (STATA Corporation, College Station, TX, USA).

\section{Results}

\section{Study inclusion}

The flowchart of literatures searched and included at each stage of analysis were shown in Figure 1. After the initial keywords search, 126 articles were included, of which 39 repetitive literatures were removed, and 50 irrelevant literatures were excluded by reading titles and abstracts. Read the full text of the remaining 37 articles, excluding 5 abstracts, 3 reviews and 17 irrelevant results. Finally, 12 literatures were included in this meta-analysis[11, 12, 19-28].

\section{Study characteristics}

A total of 12 studies ( $n=3641$ patients) published between 2015 to 2020 were included in this meta-analysis. All 12 studies used standardized intravenous thrombolytic therapy for AIS patients: rt-PA $(0.9 \mathrm{mg} / \mathrm{kg}$ body weight, maximum $90 \mathrm{mg})$ was injected intravenously within $4.5 \mathrm{~h}$ after the onset of ischemic stroke, with $10 \%$ of the total dose as a bolus and the rest by a 60 minute infusion. Blood samples were collected on admission $(n=5)[19,21,23,27,28]$ and within 24 hours after IVT $(n=3)[12,24$, 26], 4 studies were collected at both two times[11, 20, 22, 25]. HT (including symptomatic intracerebral hemorrhage and parenchymal hemorrhage), mRS at 3 months, mortality were reported in 6,10 , and 4 articles. The best cut-off values of NLR ranging from 2.2 to 10.59 . Since all the 12 studies were cohort studies, we used NOS for quality assessment, with a score range 6 to 8 points. For the basic characteristics and quality assessment of the 12 included studies were demonstrated in Table1. 


\section{Meta-analysis}

\section{Hemorrhagic transformation}

Six studies reported the relationship between NLR and HT after IVT[11, 12, 19, 22, 25, 27]. Higher NLR levels were associated with an increased risk of HT $(\mathrm{OR}=1.33,95 \% \mathrm{Cl}=1.14-1.56, P<0.001)$. Significant heterogeneity between studies were observed $\left(I^{2}=71.8 \%, P<0.001\right)$ (Figure2).

\section{Functional outcome}

Ten studies reported the association between NLR and 3-month poor functional outcome (mRS $\geq 3$ ) after IVT[11, 19-26, 28]. Higher NLR levels were associated with higher risk of 3-month poor functional outcome $(\mathrm{OR}=1.64,95 \% \mathrm{Cl}=1.38-1.94, P<0.001)$, significant heterogeneity between studies were found $\left(I^{2}=86.3 \%, P<0.001\right)$ (Figure3).

\section{Mortality}

Four studies showed the relationship between NLR and 3-month mortality[19, 21, 22, 26]. There was no significant association between higher NLR levels and higher risk of 3-month mortality $(\mathrm{OR}=1.14,95 \% \mathrm{Cl}=0.97-1.35, P=0.120)$. Moreover, significant heterogeneity between studies were observed $\left(I^{2}=81.0 \%, P<0.001\right)$ (Figure4).

\section{Subgroup analysis}

In subgroup analysis, studies were divided according to time of blood sample collection, age, country, presence or absence of infection, stroke severity and onset-to-IVT time. Subgroup analysis of HT suggested that admission NLR levels rather than postIVT NLR levels was associated with increased risk of $\mathrm{HT}(\mathrm{OR}=1.33,95 \% \mathrm{Cl}=1.01-1.75, P=0.039)$. Higher risk of HT was observed in elderly group $(\mathrm{OR}=1.32,95 \% \mathrm{Cl}=1.11-1.57, P=0.002)$. Higher NLR levels were associated with higher risk of HT in the studies excluded infection ( $\mathrm{OR}=1.64,95 \% \mathrm{Cl}=1.14-2.35, P=0.008)$. Interestingly, the onset-to-IVT time less than 3 hours was associated with higher risk of $\mathrm{HT}(\mathrm{OR}=1.32,95 \% \mathrm{Cl}=1.11-1.57, P<0.001)$. Regardless of the country and the stroke severity, the relationship between NLR and HT remains significant (Table2).

In addition, subgroup analysis of 3-month poor functional outcome suggested that blood sample collection time, age, country, onset-to-IVT time and presence or absence of infection had no significant influence on the overall results. Higher NLR levels were associated with higher risk of poor functional outcome in the studies with moderate stroke severity (NIHSS $\geq 8)$ $(\mathrm{OR}=2.15,95 \% \mathrm{Cl}=1.50-3.09, P<0.001)$ (Table2).

\section{Publication bias and sensitivity analysis}

The evidence of publication bias in the studies of those provide HT and functional outcomes were detected by Egger test ( $P=0.019$ and $P=0.001$, respectively). After the trim-and-fill test, the pooled OR were 1.31(0.99-1.72) and 1.42(0.86-2.36), respectively (Table $\mathrm{S} 1)$.

Sensitivity analysis showed that no studies have affected the effects of the pooled OR, indicating that the results of this metaanalysis were stable (Figure S1, S2).

\section{Discussion}

This meta-analysis showed that higher NLR levels were associated with higher risk of HT and 3-month poor functional outcome in AIS patients receiving IVT, while higher NLR levels were not associated with higher risk of 3-month mortality. Moreover, this meta-analysis suggested that admission NLR rather than post-IVT NLR was associated with increased risk of HT. These results may helpful for clinicians to identify the high-risk groups of HT and poor functional outcome after IVT thereby providing appropriate intervention measures. 
Some meta-analyses have showed that NLR was a biomarker of prognosis after ischemic stroke[9, 10], but this meta-analysis was the first research to comprehensively evaluate the relationship between NLR and poor prognosis in AIS patients receiving IVT. Regardless of the blood sample collection time, higher NLR levels were associated with higher risk of 3-month poor functional outcome. Importantly, post-IVT NLR seemed to have a stronger correlation than admission NLR with 3-month poor functional outcome. In addition, the best cut-off values of NLR to predict HT were 4.8[19], 7.4[25], 10.59[12], the best cut-off values of NLR to predict poor functional outcome were 2.2[21], 3.375[23], 3.6[25], 5.23[24]. Furthermore, we tried to determine the best threshold for NLR, but limited data prevented us from doing so.

The underlying mechanism of NLR to predict the clinical outcomes of AIS patients receiving IVT had not been elucidated, and one explanation may be that it combined the inflammatory destruction of neutrophils and the protective effect of lymphocytes. Neutrophils were rapidly recruited to the ischemic area and microglia were activated after cerebral infarction[5]. Neutrophils released ROS and a variety of inflammatory mediators, chemokines, cytokines, adhesion molecules and proteases to destroy the blood-brain barrier (BBB) to aggravate ischemic injury and brain edema[6, 29]. Furthermore, neutrophils have been proved to be an important source of matrix metalloproteinase-9 (MMP-9)[30]. MMP-9 was thought to be related to the destruction of the BBB and HT[31]. The rt-PA could not only promote neutrophils to release MMPs but also promote the migration of neutrophils to ischemic tissue through the proteolysis of plasmin and gelatinase[4]. Moreover, it was found that rt-PA could induce neutrophil degranulation in vitro[32]. Although reperfusion after IVT was an ideal result, regretfully it would produce more ROS[33]. ROS stimulated microglia and ischemic cells to release inflammatory cytokines and chemokines, resulting in upregulation of adhesion molecules in cerebral vessels, which made more neutrophils recruit to the infarct area and contributed to the formation of positive feedback of inflammation after stroke[29, 34]. Lymphocytes played an important role in the protective mechanism of ischemic brain tissue, in which regulatory T cells (Tregs) were important brain protective immunomodulators in ischemic stroke[7]. However, the interaction between the brain and the immune system could lead to systemic immunosuppression in the acute phase of cerebral infarction[8]. Moreover, stress response leaded to an increase in the release of glucocorticoids from the hypothalamus-pituitary axis and an increase in the production of catecholamines in the overactivated sympathetic nervous system, resulting in a decrease in the number and activity of lymphocytes[8]. Kim et.al confirmed that lower lymphocyte count was related to the poor outcomes in AIS patients at 3 months[35].

NLR was a readily available and inexpensive inflammatory biomarker, which comprehensively reflected the changes of neutrophils and lymphocytes and provided more information than neutrophils or lymphocytes alone. This meta-analysis showed that higher NLR levels were associated with higher risk of HT and 3-month poor functional outcome in AIS patients receiving IVT, but considering the limitations of the predictive value of a single biomarker, we suggested that NLR could be used as a score item of a new prognostic model to predict the clinical outcomes after IVT. In addition, anti-inflammatory therapy may be a potential stroke treatment strategy[36], but previous neutrophil inhibition trials (Enlimomab, LeukArrest and ASTIN) had not achieved the desired results in human trials[37-39]. To explore the molecular mechanism of adverse outcomes after stroke caused by neutropenia may provide a new therapeutic target for stroke treatment and neuroprotection.

Significant heterogeneity between studies were found in this meta-analysis. Subgroup analyses of HT suggested that heterogeneity reduced to $48.7 \%$ in the studies which collected blood sample on admission and reduced to $30.4 \%$ in the studies with mild stroke severity, indicating that the blood sample collection time and stroke severity may be the source of heterogeneity. In addition, significant publication bias was observed. It is necessary for future studies to publish negative results to avoid overestimating the predictive value of NLR for prognosis in AIS patients receiving IVT.

There were still some limitations in this meta-analysis. First of all, some of the studies did not strictly limit infection before admission or after stroke, but NLR was an important indicator of infection[34], which may had some impact on the overall conclusion. Second, the number of studies included in this meta-analysis was limited, larger samples and high-quality studies are needed in the future. Third, the best cut-off values of NLR varied in the included studies, which prevented us to determine an optimal threshold of NLR. Fourth, all the studies were cohort studies, most of them were retrospective studies, and each study has a certain risk of bias.

\section{Conclusion}


Higher NLR levels were associated with higher risk of HT and 3-month poor functional outcome in AIS patients receiving IVT. Admission NLR rather than post-IVT NLR were independent risk factors of increased risk of HT.

\section{Abbreviations}

NLR: Neutrophil to lymphocyte ratio; AIS: Acute ischemic stroke; IVT: Intravenous thrombolysis; OR: Odds ratios; $95 \%$ Cl: $95 \%$ confidence intervals; HT: Hemorrhagic transformation; mRS: Modified Rankin Scale; rt-PA: Recombinant tissue-plasminogen activator; ROS: Reactive oxygen species; NOS: Newcastle-Ottawa Scale; BBB: Blood-brain barrier

\section{Declarations}

\section{Ethics approval and consent to participate}

Not applicable.

\section{Consent for publication}

Not applicable.

\section{Availability of data and materials}

Data generated or analyzed during this study are included in this published article.

\section{Competing interests}

The authors declare that they have no competing interests.

\section{Funding}

Not applicable.

\section{Authors' contributions}

CBW screened the literature, extracted the data and drafted the manuscript. QZ screened the literature. MWJ extracted the data. JM and ZXX designed the study, provided consultation and revised the manuscript. All authors read and approved the final manuscript.

\section{Acknowledgements}

Not applicable.

\section{References}

1. Virani SS, Alonso A, Benjamin EJ, et al. Heart Disease and Stroke Statistics-2020 Update: A Report From the American Heart Association. Circulation. 2020;141(9):e139-e596.

2. Powers WJ, Rabinstein AA, Ackerson T, et al. Guidelines for the Early Management of Patients With Acute Ischemic Stroke: 2019 Update to the 2018 Guidelines for the Early Management of Acute Ischemic Stroke: A Guideline for Healthcare Professionals From the American Heart Association/American Stroke Association. Stroke. 2019;50(12):e344-e418.

3. Emberson J, Lees KR, Lyden P, et al. Effect of treatment delay, age, and stroke severity on the effects of intravenous thrombolysis with alteplase for acute ischaemic stroke: a meta-analysis of individual patient data from randomised trials. The Lancet. 2014;384(9958):1929-35.

4. Ma G, Pan Z, Kong L, et al. Neuroinflammation in hemorrhagic transformation after tissue plasminogen activator thrombolysis: Potential mechanisms, targets, therapeutic drugs and biomarkers. International Immunopharmacology. 
2021;90:107216.

5. Kim JY, Park J, Chang JY, et al. Inflammation after Ischemic Stroke: The Role of Leukocytes and Glial Cells. Experimental neurobiology. 2016;25(5):241-51.

6. Jickling GC, Liu D, Ander BP, et al. Targeting neutrophils in ischemic stroke: translational insights from experimental studies. Journal of cerebral blood flow and metabolism : official journal of the International Society of Cerebral Blood Flow and Metabolism. 2015;35(6):888-901.

7. Liesz A, Suri-Payer E, Veltkamp C, et al. Regulatory T cells are key cerebroprotective immunomodulators in acute experimental stroke. Nature medicine. 2009;15(2):192-9.

8. Liu DD, Chu SF, Chen C, et al. Research progress in stroke-induced immunodepression syndrome (SIDS) and strokeassociated pneumonia (SAP). Neurochemistry international. 2018;114:42-54.

9. Wang L, Song Q, Wang C, et al. Neutrophil to lymphocyte ratio predicts poor outcomes after acute ischemic stroke: A cohort study and systematic review. J Neurol Sci. 2019;406:116445.

10. Song SY, Zhao XX, Rajah G, et al. Clinical Significance of Baseline Neutrophil-to-Lymphocyte Ratio in Patients With Ischemic Stroke or Hemorrhagic Stroke: An Updated Meta-Analysis. Frontiers in neurology. 2019;10:1032.

11. Ying $A$, Cheng $Y$, Lin $Y$, et al. Dynamic increase in neutrophil levels predicts parenchymal hemorrhage and function outcome of ischemic stroke with r-tPA thrombolysis. Neurol Sci. 2020 Aug;41(8):2215-23.

12. Guo Z, Yu S, Xiao L, et al. Dynamic change of neutrophil to lymphocyte ratio and hemorrhagic transformation after thrombolysis in stroke. Journal of Neuroinflammation. 2016;13(1).

13. Moher D, Liberati A, Tetzlaff J, et al. Preferred reporting items for systematic reviews and meta-analyses: the PRISMA statement. BMJ (Clinical research ed). 2009;339:b2535.

14. Stang A. Critical evaluation of the Newcastle-Ottawa scale for the assessment of the quality of nonrandomized studies in meta-analyses. European journal of epidemiology. 2010;25(9):603-5.

15. Higgins JP, Thompson SG, Deeks JJ, et al. Measuring inconsistency in meta-analyses. BMJ (Clinical research ed). 2003;327(7414):557-60.

16. Higgins JP, Thompson SG. Quantifying heterogeneity in a meta-analysis. Statistics in medicine. 2002;21(11):1539-58.

17. Egger M, Davey Smith G, Schneider M, et al. Bias in meta-analysis detected by a simple, graphical test. BMJ (Clinical research ed). 1997;315(7109):629-34.

18. Duval S, Tweedie R. Trim and fill: A simple funnel-plot-based method of testing and adjusting for publication bias in metaanalysis. Biometrics. 2000;56(2):455-63.

19. Maestrini I, Strbian D, Gautier S, et al. Higher neutrophil counts before thrombolysis for cerebral ischemia predict worse outcomes. Neurology. 2015;85(16):1408-16.

20. Pagram H, Bivard A, Lincz LF, et al. Peripheral Immune Cell Counts and Advanced Imaging as Biomarkers of Stroke Outcome. Cerebrovascular Diseases Extra. 2016;6(3):120-8.

21. Malhotra K, Goyal N, Chang JJ. Differential leukocyte counts on admission predict outcomes in patients with acute ischaemic stroke treated with intravenous thrombolysis. Eur J Neurol. 2018 Dec;25(12):1417-24.

22. Shi J, Peng H. Increase in neutrophils after recombinant tissue plasminogen activator thrombolysis predicts poor functional outcome of ischaemic stroke: a longitudinal study. Eur J Neurol. 2018 Apr;25(4):687-e45.

23. Yingying W, Jianfang Z, Yabin J, et al. Prognosis of neutrophil and lymphocyte ratio in patients with acute cerebral infarction with thrombolytic therapy. Journal of Jinan University (Nature Science \& Medicine Edition). 2018;39(01):35-40.

24. Zhiliang G, Shuhong Y, Lulu X, et al. Value of elevated neutrophil/lymphocyte ratio in predicting outcome of acute ischemic stroke patients after thrombolysis. Chin J Geriatr Heart Brain Vessel Dis. 2018;20(10):1019-22.

25. Pektezel MY, Yilmaz E, Arsava EM, et al. Neutrophil-to-Lymphocyte Ratio and Response to Intravenous Thrombolysis in Patients with Acute Ischemic Stroke. Journal of Stroke and Cerebrovascular Diseases. 2019;28(7):1853-9.

26. Cheng Y, Ying A, Lin Y, et al. Neutrophil-to-lymphocyte ratio, hyperglycemia, and outcomes in ischemic stroke patients treated with intravenous thrombolysis. Brain Behav. 2020;10(9):e01741. 
27. Liu YL, Lu JK, Yin HP. High Neutrophil-to-Lymphocyte Ratio Predicts Hemorrhagic Transformation in Acute Ischemic Stroke Patients Treated with Intravenous Thrombolysis. Int J Hypertens. 2020 Feb 27;2020:5980261.

28. Liu YL, Wu ZQ, Qu JF, et al. High neutrophil-to-lymphocyte ratio is a predictor of poor short-term outcome in patients with mild acute ischemic stroke receiving intravenous thrombolysis. Brain Behav. 2020 Dec;10(12):e01857.

29. Jin R, Liu L, Zhang S, et al. Role of inflammation and its mediators in acute ischemic stroke. Journal of cardiovascular translational research. 2013;6(5):834-51.

30. Jickling GC, Liu D, Stamova B, et al. Hemorrhagic Transformation after Ischemic Stroke in Animals and Humans. Journal of Cerebral Blood Flow \& Metabolism. 2013;34(2):185-99.

31. Inzitari D, Giusti B, Nencini P, et al. MMP9 variation after thrombolysis is associated with hemorrhagic transformation of lesion and death. Stroke. 2013;44(10):2901-3.

32. Carbone F, Vuilleumier N, Bertolotto M, et al. Treatment with recombinant tissue plasminogen activator (r-TPA) induces neutrophil degranulation in vitro via defined pathways. Vascular pharmacology. 2015;64:16-27.

33. Wang Q, Tang XN, Yenari MA. The inflammatory response in stroke. Journal of neuroimmunology. 2007;184(1-2):53-68.

34. Ruhnau J, Schulze J, Dressel A, et al. Thrombosis, Neuroinflammation, and Poststroke Infection: The Multifaceted Role of Neutrophils in Stroke. J Immunol Res. 2017;2017:5140679.

35. Kim J, Song TJ, Park JH, et al. Different prognostic value of white blood cell subtypes in patients with acute cerebral infarction. Atherosclerosis. 2012;222(2):464-7.

36. Macrez R, Ali C, Toutirais O, et al. Stroke and the immune system: from pathophysiology to new therapeutic strategies. The Lancet Neurology. 2011;10(5):471-80.

37. Krams M, Lees KR, Hacke W, et al. Acute Stroke Therapy by Inhibition of Neutrophils (ASTIN): an adaptive dose-response study of UK-279,276 in acute ischemic stroke. Stroke. 2003;34(11):2543-8.

38. Becker KJ. Anti-leukocyte antibodies: LeukArrest (Hu23F2G) and Enlimomab (R6.5) in acute stroke. Current medical research and opinion. 2002;18 Suppl 2:s18-22.

39. Investigators EAST. Use of anti-ICAM-1 therapy in ischemic stroke: results of the Enlimomab Acute Stroke Trial. Neurology. 2001;57(8):1428-34.

\section{Tables}

Table 1 Basic characteristics and quality evaluation of the included studies 


\begin{tabular}{|c|c|c|c|c|c|c|c|c|c|c|c|}
\hline Author & Year & Country & $\begin{array}{l}\text { Sample } \\
\text { size }\end{array}$ & Male(\%) & Age(year) & $\begin{array}{l}\text { Sample } \\
\text { time }\end{array}$ & HT & PFO & Death & $\begin{array}{l}\text { Cutoff } \\
\text { value }\end{array}$ & NOS \\
\hline Maestrini & 2015 & $\begin{array}{l}\text { France } \\
\text { and } \\
\text { Finland }\end{array}$ & 846 & 50.8 & $\begin{array}{l}71 \rrbracket 61- \\
80 \rrbracket\end{array}$ & $\begin{array}{l}\text { On } \\
\text { admission }\end{array}$ & $\mathrm{sICH}$ & Yes & Yes & $\begin{array}{l}4.8 \text { of } \\
\text { siCH }\end{array}$ & 7 \\
\hline Guo & 2016 & China & 189 & 65.1 & $65.0 \pm 10.6$ & $\begin{array}{l}12-18 \mathrm{~h} \\
\text { after IVT }\end{array}$ & HT & NA & NA & $\begin{array}{l}10.59 \\
\text { of HT }\end{array}$ & 7 \\
\hline Pagram & 2016 & Australia & 141 & NA & $74.3 \pm 10.7$ & $\begin{array}{l}\text { On } \\
\text { admission, } \\
24 \mathrm{~h} \text { after } \\
\text { IVT }\end{array}$ & NA & Yes & NA & NA & 6 \\
\hline Malhotra & 2018 & USA & 657 & 50.7 & $64.3 \pm 14.4$ & $\begin{array}{l}\text { On } \\
\text { admission }\end{array}$ & $\mathrm{SICH}$ & Yes & Yes & $\begin{array}{l}2.2 \text { of } \\
\text { PFO }\end{array}$ & 6 \\
\hline Shi & 2018 & China & 372 & 65.1 & $63.9 \pm 13.3$ & $\begin{array}{l}\text { On } \\
\text { admission, } \\
24 \text { h after } \\
\text { IVT }\end{array}$ & NA & Yes & Yes & NA & 8 \\
\hline Guo & 2018 & China & 105 & 64.8 & $65.7 \pm 9.8$ & $\begin{array}{l}\text { 6-8h after } \\
\text { IVT }\end{array}$ & NA & Yes & NA & $\begin{array}{l}5.23 \\
\text { of } \\
\text { PFO }\end{array}$ & 7 \\
\hline Wang & 2018 & China & 123 & 65.0 & $65.2 \pm 11.9$ & $\begin{array}{l}\text { On } \\
\text { admission }\end{array}$ & NA & Yes & NA & $\begin{array}{l}3.375 \\
\text { of } \\
\text { PFO }\end{array}$ & 7 \\
\hline Pektezel & 2019 & Turkey & 142 & 43.7 & $69 \pm 13$ & $\begin{array}{l}\text { On } \\
\text { admission, } \\
24 \mathrm{~h} \text { after } \\
\text { IVT }\end{array}$ & $\mathrm{HT}$ & Yes & NA & $\begin{array}{l}7.4 \text { of } \\
\text { siCH, } \\
3.6 \text { of } \\
\text { PFO }\end{array}$ & 7 \\
\hline Liu & 2020 & China & 285 & 70.5 & $62.3 \pm 12$ & $\begin{array}{l}\text { On } \\
\text { admission }\end{array}$ & $\mathrm{HT}$ & NA & NA & NA & 7 \\
\hline Ying & 2020 & China & 208 & 61.5 & $67.4 \pm 12.4$ & $\begin{array}{l}\text { On } \\
\text { admission, } \\
24 \mathrm{~h} \text { after } \\
\text { IVT }\end{array}$ & $\mathrm{PH}$ & Yes & NA & NA & 7 \\
\hline Liu & 2020 & China & 192 & 71.9 & $60.8 \pm 11.7$ & $\begin{array}{l}\text { On } \\
\text { admission }\end{array}$ & NA & Yes & NA & NA & 7 \\
\hline Cheng & 2020 & China & 481 & 61.9 & $\begin{array}{l}68(59- \\
76)\end{array}$ & $\begin{array}{l}\text { 24h after } \\
\text { IVT }\end{array}$ & NA & Yes & Yes & NA & 7 \\
\hline
\end{tabular}

HT: hemorrhagic transformation. PFO: poor functional outcome. NOS: Newcastle-Ottawa Scale. sICH: symptomatic intracranial hemorrhage. IVT: intravenous thrombolysis. NA: not available. PH: parenchymal hemorrhage.

Table 2 Subgroup analyses of the associations between NLR and poor prognosis in AIS patients treated with IVT 


\begin{tabular}{|c|c|c|c|c|c|c|c|c|}
\hline \multirow[t]{2}{*}{ Group } & \multicolumn{4}{|c|}{$\mathrm{HT}$} & \multicolumn{4}{|c|}{ 3-month poor functional outcome } \\
\hline & $\mathrm{N}$ & OR $(95 \% \mathrm{Cl})$ & $P$ & $\begin{array}{l}\text { Heterogeneity }\left(I^{2} \text {, }\right. \\
P)\end{array}$ & $\mathrm{N}$ & OR $(95 \% \mathrm{Cl})$ & $P$ & $\begin{array}{l}\text { Heterogeneity } \\
\left(I^{2}, P\right)\end{array}$ \\
\hline \multicolumn{9}{|l|}{ Sample time } \\
\hline On admission & 5 & $\begin{array}{l}1.33(1.01 \\
1.75)\end{array}$ & 0.039 & $48.7 \%, 0.100$ & 8 & $\begin{array}{l}1.22(1.05 \\
1.40)\end{array}$ & 0.007 & $76.1 \%,<0.001$ \\
\hline Post-IVT & 4 & $\begin{array}{l}1.88(0.97 \\
3.63)\end{array}$ & 0.061 & $84.7 \%,<0.001$ & 6 & $\begin{array}{l}2.78(1.63 \\
4.74)\end{array}$ & $<0.001$ & $84.3 \%,<0.001$ \\
\hline \multicolumn{9}{|l|}{ Age } \\
\hline$<65$ & 2 & $\begin{array}{l}1.43(0.98 \\
2.08)\end{array}$ & 0.063 & $0.0 \%, 0.393$ & 3 & $\begin{array}{l}1.83(1.01 \\
3.32)\end{array}$ & 0.045 & $87.7 \%,<0.001$ \\
\hline$\geq 65$ & 4 & $\begin{array}{l}1.32(1.11 \\
1.57)\end{array}$ & 0.002 & $80.0 \%,<0.001$ & 7 & $\begin{array}{l}1.87(1.36 \\
2.59)\end{array}$ & $<0.001$ & $87.1 \%,<0.001$ \\
\hline \multicolumn{9}{|l|}{ Country } \\
\hline Asian & 5 & $\begin{array}{l}1.68(1.20 \\
2.35)\end{array}$ & 0.003 & $73.2 \%,<0.001$ & 7 & $\begin{array}{l}1.82(1.31 \\
2.53)\end{array}$ & $<0.001$ & $75.5 \%,<0.001$ \\
\hline Non-Asian & 1 & $\begin{array}{l}1.11(1.06 \\
1.17)\end{array}$ & $<0.001$ &,-- & 3 & $\begin{array}{l}1.37(1.12, \\
1.68)\end{array}$ & 0.002 & $92.1 \%,<0.001$ \\
\hline \multicolumn{9}{|l|}{$\begin{array}{l}\text { Infection } \\
\text { excluded }\end{array}$} \\
\hline Yes & 4 & $\begin{array}{l}1.64(1.14 \\
2.35)\end{array}$ & 0.008 & $74.2 \%, 0.001$ & 6 & $\begin{array}{l}1.75(1.24 \\
2.48)\end{array}$ & 0.002 & $75.9 \%,<0.001$ \\
\hline No & 2 & $\begin{array}{l}1.39(0.77 \\
2.51)\end{array}$ & 0.274 & $71.4 \%, 0.062$ & 4 & $\begin{array}{l}1.50(1.22 \\
1.85)\end{array}$ & $<0.001$ & $91.5 \%,<0.001$ \\
\hline \multicolumn{9}{|l|}{ Stroke severity } \\
\hline $\mathrm{NIHSS}<8$ & 2 & $\begin{array}{l}1.69(1.11 \\
2.56)\end{array}$ & 0.014 & $30.4 \%, 0.238$ & 4 & $\begin{array}{l}1.34(0.91 \\
1.96)\end{array}$ & 0.135 & $70.7 \%, 0.008$ \\
\hline $\mathrm{NIHSS} \geq 8$ & 4 & $\begin{array}{l}1.25(1.07 \\
1.47)\end{array}$ & 0.006 & $76.1 \%, 0.001$ & 6 & $\begin{array}{l}2.15(1.50 \\
3.09)\end{array}$ & $<0.001$ & $89.9 \%,<0.001$ \\
\hline \multicolumn{9}{|l|}{$\begin{array}{l}\text { Onset-to-IVT } \\
\text { time }\end{array}$} \\
\hline$\leq 3 h$ & 4 & $\begin{array}{l}1.32(1.11 \\
1.57)\end{array}$ & 0.002 & $80.0 \%,<0.001$ & 6 & $\begin{array}{l}1.24(1.09 \\
1.42)\end{array}$ & 0.001 & $77.6 \%,<0.001$ \\
\hline $3-4.5 h$ & 2 & $\begin{array}{l}1.43(0.98 \\
2.08)\end{array}$ & 0.063 & $0.0 \%, 0.393$ & 3 & $\begin{array}{l}2.52 \\
(1.19,5.30)\end{array}$ & 0.015 & $78.0 \%, 0.003$ \\
\hline
\end{tabular}

NLR: neutrophil to lymphocyte ratio. HT: hemorrhagic transformation. AIS: acute ischemic stroke. IVT: intravenous thrombolysis. N: number of studies. OR: odds ratio. NIHSS: National Institutes of Health Stroke Scale.

Figures 


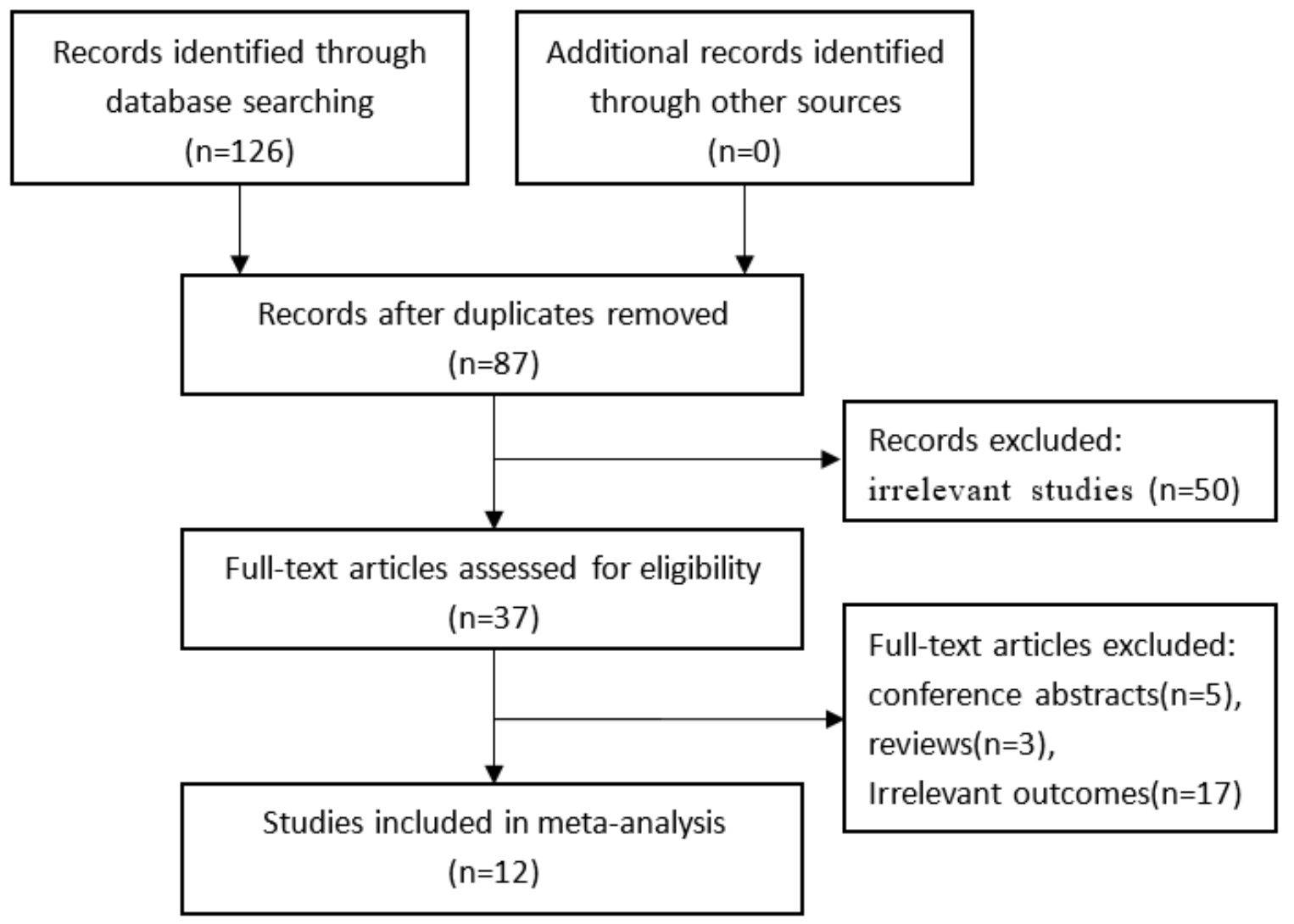

Figure 1

Flow diagram of literatures search and studies selection. 
Study

ID

OR $(95 \% \mathrm{Cl}) \quad$ Weight

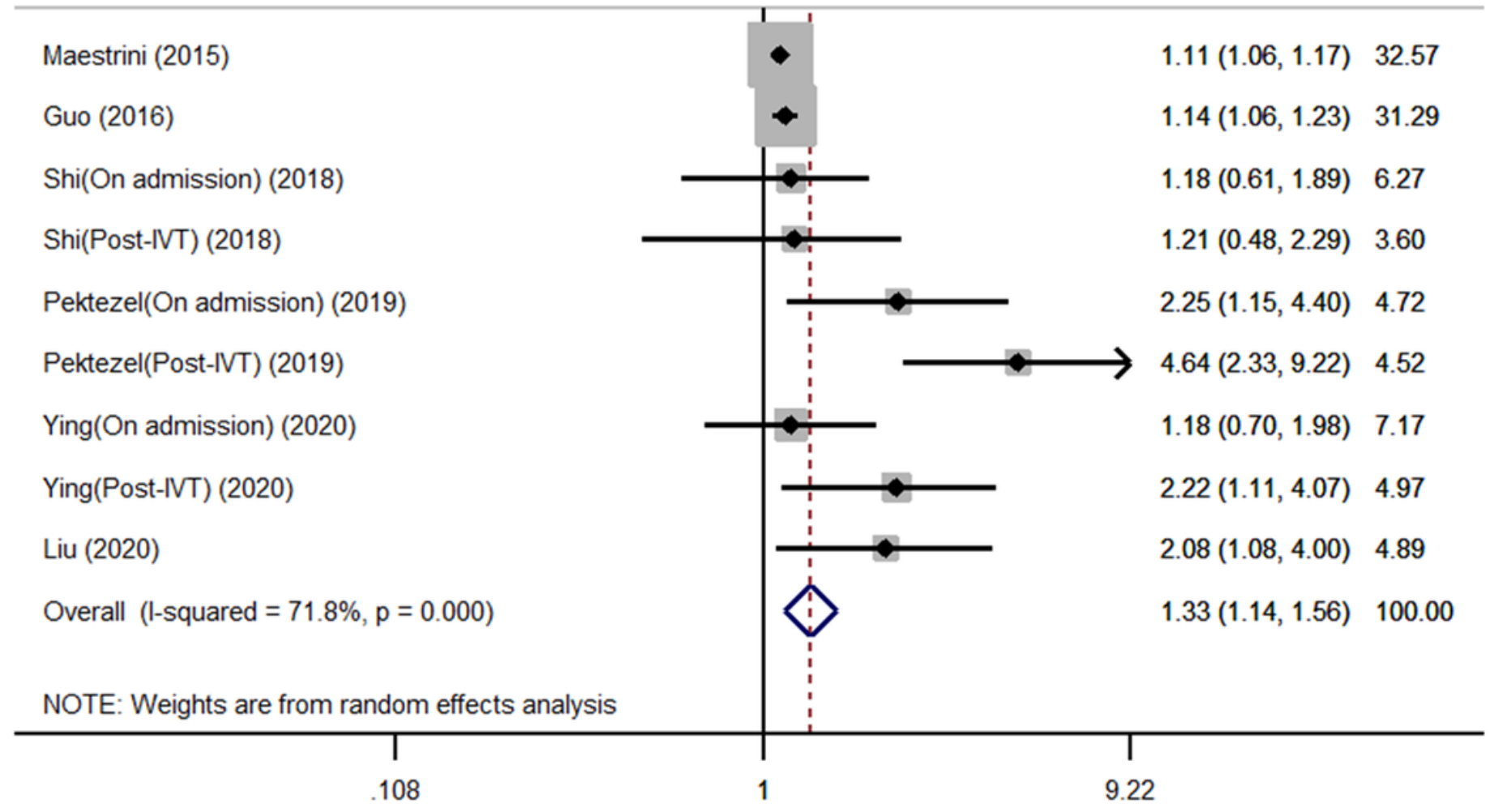

Figure 2

Pooled odds ratio of NLR for HT in AIS patients treated with IVT. 
Study

$\%$

ID

OR (95\% Cl)

Weight

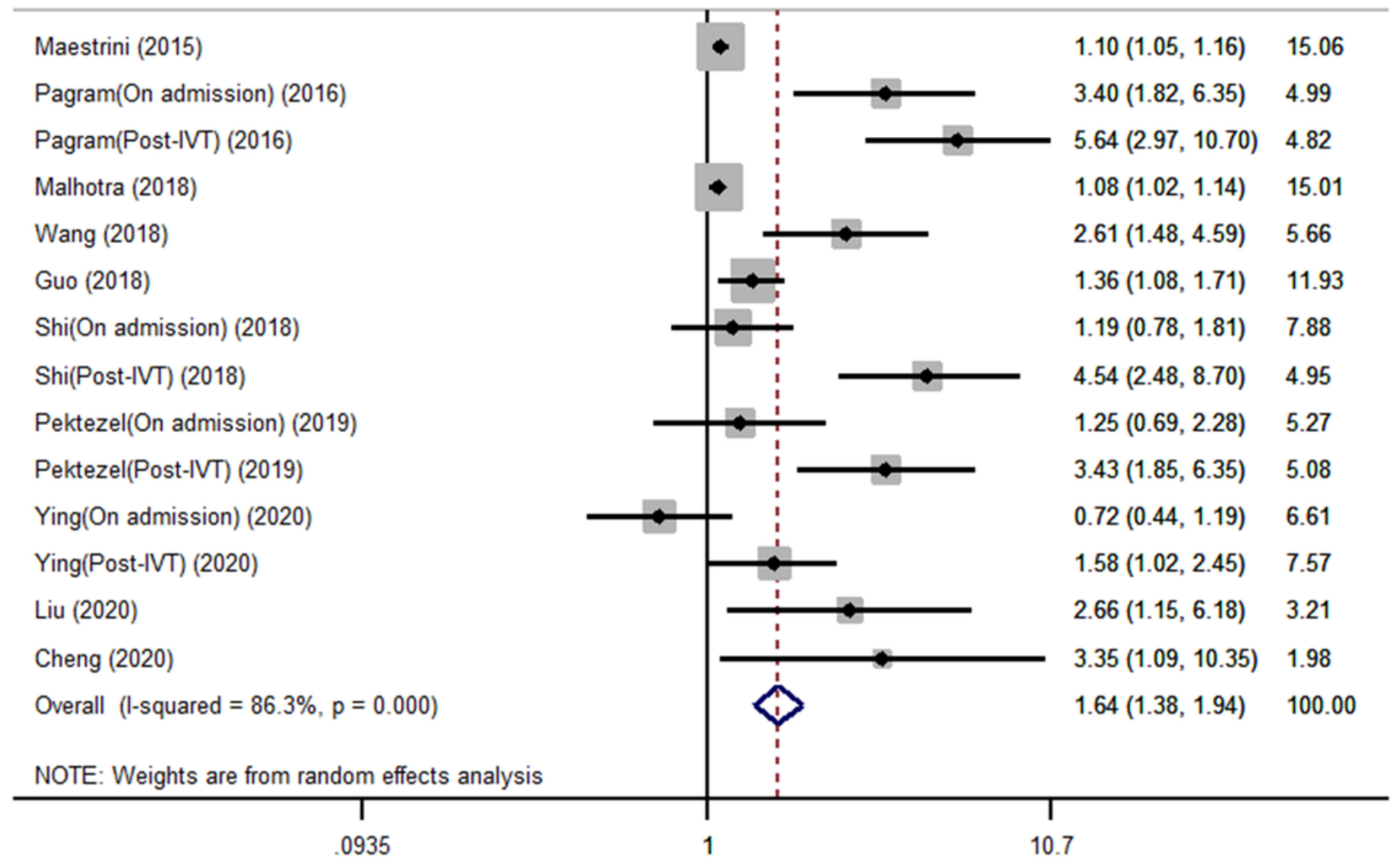

Figure 3

Pooled odds ratio of NLR for functional outcomes in AIS patients treated with IVT. 
ID

OR $(95 \% \mathrm{Cl})$

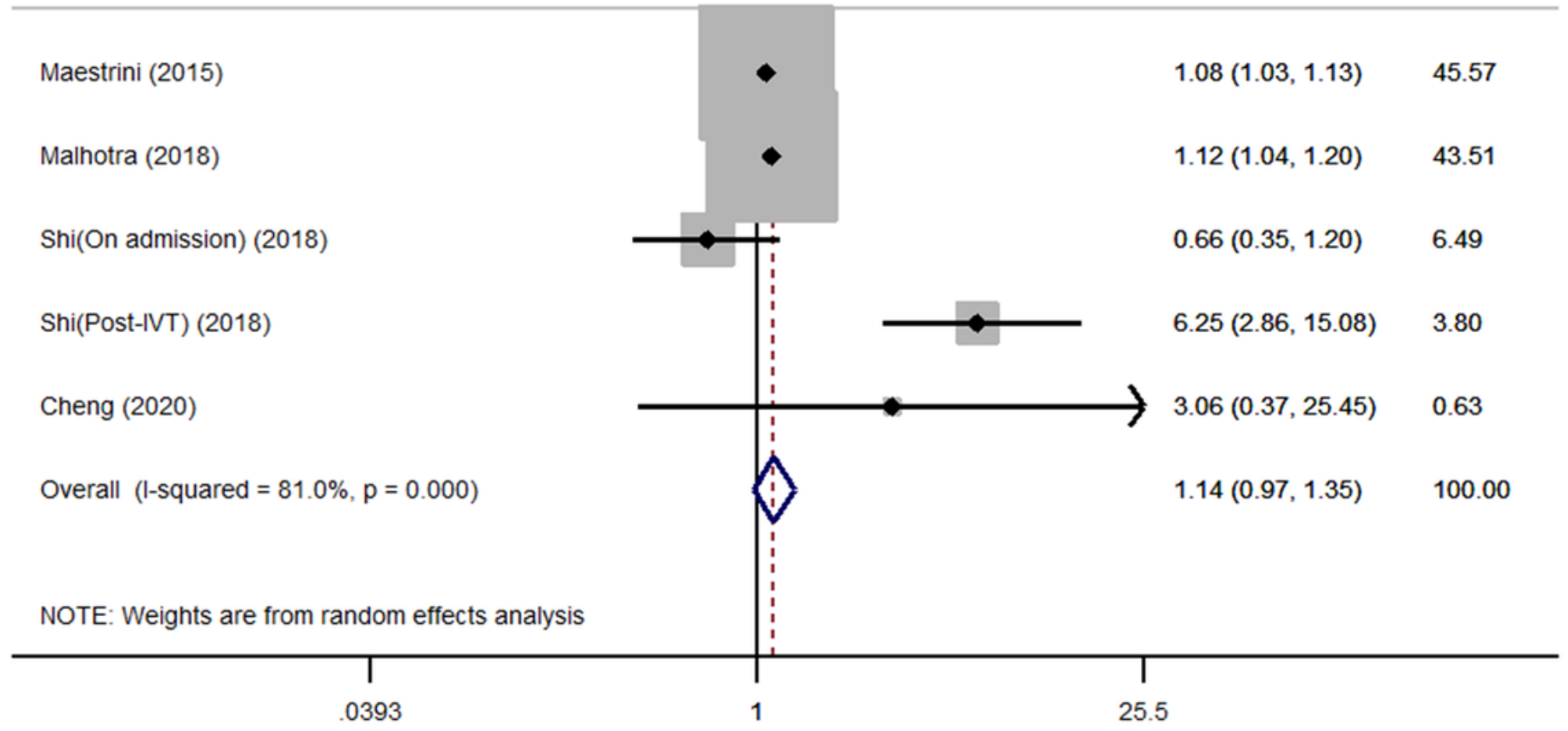

Figure 4

Pooled odds ratio of NLR for mortality in AIS patients treated with IVT.

\section{Supplementary Files}

This is a list of supplementary files associated with this preprint. Click to download.

- TableS1.docx

- Figures1.docx

- Figures2.docx 